\title{
Morphological Study of Human Placenta in Normal and Hypertensive Pregnancy
}

\author{
K.M.Parmar', Hetal Vaishnani ${ }^{2}$, G.V.Shah ${ }^{3}$ \\ ${ }_{1}^{1}$ Assistant Professor, Department of Anatomy, Smt. B.K. Shah Medical institute \& Research Centre, Sumandeep Vidyapeeth, Piparia, Vadodara, Gujarat, \\ ${ }^{2}$ Associate Professor, Department of Anatomy, Smt. B.K. Shah Medical institute \& Research Centre, Sumandeep Vidyapeeth, Piparia, Vadodara, Gujarat, \\ ${ }^{3}$ Dean, Department of Anatomy, Smt. B.K. Shah Medical institute \& Research Centre, Sumandeep Vidyapeeth, Piparia, Vadodara, Gujarat.
}

\section{Abstract}

Introduction: The normal human placenta is a dynamic discoid organ have two surfaces; 1 . The chorionic plate facing the foetus (the umbilical cord attached) and 2. The basal plate which about the maternal endometrium. Human placenta has drawn attention as valuable information regarding foetal \& maternal diseases. As placenta guide the intra uterine status of the foetus, study of the placenta will give an accurate condition of the foetal outcome. The aim of this study was to study the morphology of placenta with normal \& hypertensive mother. Subjects and Methods: This present study was carried out in the Dept. of Anatomy, Smt. B. K. Shah Medical institute \& Research Centre, in association with the dept. of OB \& GY of Dhiraj hospital, Piparia, Waghodia, Vadodara district. A total number of 100 (Hundred) placenta (50 - fifty hypertensive mother +50 - fifty normal mother) with $5 \mathrm{cms}$ length of umbilical cord were collected from the Obstetric dept. and relevant medical history $(\mathrm{H} / \mathrm{O})$ related of the mother were noted and recorded from the data available in the hospital record section. Results and Conclusion: In this present study group comprised human placentae from fifty (50) pregnancies with hypertensive mother. The control group comprised fifty (50) human placentae from pregnant mothers with normal blood pressure, without proteinuria and without edema. Among study group most common pregnancy comprised pre-eclampsia (50\%) in this study. The mean age of hypertensive mothers were $25.9 \pm 2.5$ years in this present study. The mean age of non-hypertensive mother were $25.1 \pm 3.21$ in this present study.

Keywords: Placenta, hypertension, pregnancy, Morphology

Corresponding Author: Dr. Hetal Vaishnani, Associate Professor, Department of Anatomy, Smt. B.K. Shah Medical institute \& Research Centre, Sumandeep Vidyapeeth, Piparia, PIN : 391760, Vadodara, Gujarat.

Received: July 2019

Accepted: July 2019

\section{Introduction}

The human placenta is a dynamic discoid organ which has two surfaces; one the chorionic plate facing the foetus (umbilical cord attached) \& the basal plate which about the maternal endometrium (Wang et al., 2004; Sørensen et al., 2013. ${ }^{[1,2]}$

It is the only organ in the body from two separate individuals, first from mother and second from the foetus and is the primary metabolic regulator for the respiratory system, excretory function, nutritional deficiency, endocrine and immunological functions of the foetus necessary for the foetal growth, Raghunath \& Vijayalakshmi et al .2011; Singal et al., 2013. . $^{3,4]}$

The normal human placenta at term pregnancy has a dark blue red colour / maroon colour and weighs about 590 grams and is appx. 20 to $25 \mathrm{~cm}$ in diameter and $3 \mathrm{~cm}$ thick, Tissot van Patot et al., 2009; Heazell et al., 2010. ${ }^{[5,6]}$ These morphological measurements can vary considerably due to many factors including pathological and physiological factors, Janthanaphan et al., 2006; Kaplan, 2008. ${ }^{[7,8]}$

The normal weight of the placenta has been varied over the years but recent studies show that it has an average weight of about 590 grams with a range of 350 to 750 grams Panti et al., 2012; Lakshmi et al., 2013. ${ }^{[9,10]}$ It has been shown that placental weight has a significant role in foetal growth in terms of weight, body length, and cord length but it has no significant role in the presence of meconium - stained fluid Lo et al., 2002. ${ }^{[11]}$ Little et al. (2003) reported that absolute measures of infant size and placental weight had mutual positive correlation. ${ }^{[12]}$

Placenta drawn attention towards valuable information related to foetal \& maternal diseases. ${ }^{[13]}$

Eskild A,Vatten LJ, many disorders related to pregnancy which are associated with high risk peri natal morbidity \& mortality, shown gross pathological changes in human placenta. Many maternal diseases and disorders bring about to notice for changes in placenta at morphological and microscopic level. Abnormal results of placenta adversely affects the fetal outcome. ${ }^{[14]}$

Udaina.A \& Majumdar S, as placenta is the mirror of maternal and foetal outcome, complications in pregnancy has been reflected in the placenta in a significant way both macroscopically \& microscopically. ${ }^{[15-18]}$ 


\section{Parmar et al; HHuman Placenta in Narmal and Hypertensive Pregnancy}

As placenta guide the condition of intra uterine status of the foetus, study of the placenta give an accurate outcome of the foetal condition (Manik Sirpurkar et al). ${ }^{[19]}$

Benirschke. K \& Carolyn M, life threatening complications of human pregnancy like gestational diabetes, iron deficiency anaemia, hypertension \& intra uterine growth retardation (IUGR) result in both macroscopic as well as microscopic changes in the placenta. ${ }^{[20,21]}$

Maternal hypertension, a global epidemic in 21 stcentury pregnancy complication \& became one among the deadly triad along with hemorrhage and infection in preganncy resulting in large number of maternal deaths and there off fetal deaths. Choe Jing Jye, PIH (Pregnancy induce Hypertension) is a pregnancy specific, multi-systemic disorder characterized by hypertension, edema and proteinuria after twenty weeks (20 weeks) of gestation. ${ }^{[22]}$ Emery SP, pregnancy complicated by hypertension is commonly associated with placental insufficiency. ${ }^{[23]}$ Bewly $\mathrm{S}$, has recorded that maternal utero-placental blood flow is reduced in pre-eclampsia because there is maternal vasospasm. ${ }^{[2]}$ Hypoxia in inter-villous space due to reduction of blood flow in placenta \& myometrium is involved in the mechanisms of morphological alterations of the placenta because of maternal hypertension (Alvarez $\mathrm{H}$ et al). ${ }^{[25]}$

The feature of abnormal placentation in PIH (Pregnancy induce hypertension) is inadequate trophoblastic invasion of maternal spiral arteries that results in persistence of muscular \& elastic tissues in tunica media. Blood vessels fail to dilate, remain responsive to vasomotor influences that lead to high resistance low flow chorio-decidual circulation. ${ }^{[26]}$ This results in morphological \& histological changes in ischemic placentae and fetal hypoxia leading to intra uterine growth retardation (IUGR) which contributes to premature delivery \& fetal death (Zhou Y et al). ${ }^{[27]}$

\section{Subjects and Methods}

This present study was conducted in the dept. of anatomy, Smt. B.K. Shah Medical institute \& Research Centre with dept. of OB \& GY of Dhiraj hospital, Piparia, Waghodia Vadodara.

A total no. of 100 (Hundred) placenta (50- Fifty hypertensive mother +50 - fifty normal mother) with Five (5) $\mathrm{cms}$ length of umbilical cord of studied subjects were collected from the Obstetrics dept. \& relevant medical history of the mother were noted from the data available in the Hospital record section.

The studied specimens of placenta and cord were brought to the dept. of anatomy. The placenta and cord washed with water to remove the blood clots \& make them dry.

The following data were recorded for the study (Weight,
Consistency, Shape Cord attachment, Thickness of placenta is measured by inserting the fine needle through \& through and measured upto nearest millimeters, Diameter of the placenta is measured by taking as average of the diameter with measuring tape). There were present or absent (hematoma, calcification, infarction) noted.

This study comprised 1. Study group: fifty (50) placentae from pregnancies with hypertension (PIH). Those pregnant women who had blood pressure at or above 140/90 mmhg. Involved in hypertensive group. 2. Control group comprised fifty placentae from pregnant women with normal blood pressure.

\section{Results}

In present study hypertensive mother group (study group), maximum number of placentae were from the Pre eclamptic mothers.

Table 1: Distribution of study group
\begin{tabular}{|l|l|l|}
\hline Type of Pregnancy & No. of Cases & Percentage (\%) \\
\hline Gestational Hypertension & 13 & $26 \%$ \\
\hline Pre-eclampsia & 25 & $50 \%$ \\
\hline Eclampsia & 12 & $24 \%$ \\
\hline Total & 50 & $100 \%$ \\
\hline
\end{tabular}

The study group comprised placentae from fifty pregnancies with hypertension. The control group comprised fifty placentae from pregnant mothers with normal blood pressure, without proteinuria and without edema. Among study group most common pregnancy comprised preeclampsia $(50 \%)$.

Table 2: Comparison according to maternal age.

\begin{tabular}{|l|l|l|}
\hline $\begin{array}{l}\text { Age Group } \\
\text { (Years) }\end{array}$ & Hypertensive (Study) & Normal (Control) \\
\hline $20-24$ & 16 & 12 \\
\hline $25-29$ & 24 & 30 \\
\hline $30-35$ & 10 & 08 \\
\hline Total & 50 & 50 \\
\hline Mean \pm SD & $25.9 \pm 2.5$ & $25.1 \pm 3.21$ \\
\hline
\end{tabular}

The mean age of hypertensive mothers was $25.9 \pm 2.5$ years. The mean age of non-hypertensive mother was $25.1 \pm 3.21$.

\begin{tabular}{l}
\hline Table 3: Distribution related to parity. \\
\begin{tabular}{|l|l|l|l|}
\hline Partiy & $\begin{array}{l}\text { Hypertensive } \\
\text { Mothers }\end{array}$ & $\begin{array}{l}\text { Normal } \\
\text { mothers }\end{array}$ & Total \\
\hline Primi & 40 & 38 & 78 \\
\hline Multi & 10 & 12 & 22 \\
\hline Total & 50 & 50 & 100 \\
\hline
\end{tabular}
\end{tabular}

Above table suggest maximum no of hypertensive mothers were primi para and also maximum no in normal mothers. There was no significant difference between this two groups.

\begin{tabular}{|c|c|c|c|c|c|c|c|}
\hline \multirow{2}{*}{ No } & \multirow{2}{*}{$\begin{array}{l}\text { Pregnancy } \\
\text { outcome }\end{array}$} & \multirow{2}{*}{ 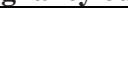 } & \multicolumn{2}{|c|}{ Hypertensive mothers } & \multicolumn{2}{|c|}{ Non hypertensive mothers } & \multirow{2}{*}{ Significance } \\
\hline & & & No & $\%$ & No & $\%$ & \\
\hline \multirow[t]{2}{*}{1} & \multirow[t]{2}{*}{ Mode of delivery } & Vaginal & 28 & $56 \%$ & 36 & $72 \%$ & \multirow[t]{2}{*}{$\mathrm{p}<0.001$} \\
\hline & & LSCS & 22 & $44 \%$ & 14 & $28 \%$ & \\
\hline \multirow[t]{2}{*}{2} & \multirow[t]{2}{*}{ Term of baby } & Pre Term & 19 & $38 \%$ & 01 & $02 \%$ & \multirow[t]{2}{*}{$\mathrm{P}<0.01$} \\
\hline & & Term & 31 & $62 \%$ & 49 & $98 \%$ & \\
\hline \multirow[t]{2}{*}{3} & \multirow[t]{2}{*}{ Type of birth } & Live & 45 & $90 \%$ & 50 & $100 \%$ & \multirow[t]{2}{*}{$\mathrm{P}<0.001$} \\
\hline & & IUD & 05 & $10 \%$ & 00 & 00 & \\
\hline
\end{tabular}




\section{Parmar et al; Htuman Placenta in Narmal and Ftypertensive Pregnancy}

Table 5: Gross morphology of Placenta

\begin{tabular}{|c|c|c|c|c|c|c|c|}
\hline \multirow[t]{2}{*}{ No } & \multirow[t]{2}{*}{ Features of Placenta } & \multirow[t]{2}{*}{ Component } & \multicolumn{2}{|c|}{ Hypertensive } & \multicolumn{2}{|c|}{ Non hypertensive } & \multirow[t]{2}{*}{ Significance } \\
\hline & & & No & $\%$ & No & $\%$ & \\
\hline \multirow[t]{2}{*}{1} & \multirow[t]{2}{*}{ Shape } & Discoid & 29 & $58 \%$ & 49 & $98 \%$ & \multirow[t]{2}{*}{$\mathrm{P}<0.01$} \\
\hline & & Irregular & 21 & $42 \%$ & 01 & $02 \%$ & \\
\hline \multirow[t]{2}{*}{2} & \multirow[t]{2}{*}{ Hematoma } & Absent & 42 & $82 \%$ & 50 & $100 \%$ & \multirow[t]{2}{*}{$\mathrm{P}<0.05$} \\
\hline & & Present & 08 & $16 \%$ & 00 & 0 & \\
\hline \multirow[t]{2}{*}{3} & \multirow[t]{2}{*}{ Infarction } & Absent & 40 & $80 \%$ & 48 & $96 \%$ & \multirow[t]{2}{*}{$\mathrm{P}<0.001$} \\
\hline & & Present & 10 & $20 \%$ & 02 & $04 \%$ & \\
\hline \multirow[t]{2}{*}{4} & \multirow[t]{2}{*}{ Calcification } & Absent & 27 & $54 \%$ & 42 & $84 \%$ & \multirow[t]{2}{*}{$\mathrm{P}<0.01$} \\
\hline & & Present & 23 & $46 \%$ & 08 & $16 \%$ & \\
\hline
\end{tabular}

The above table suggest that, hypertensive mothers delivered $56 \%$ vaginal, $44 \%$ LSCS and non-hypertensive mothers delivered $72 \%$ vaginal, $28 \%$ LSCS. In hypertensive mother's $38 \%$ pre term and $62 \%$ Term baby and in nonhypertensive mothers $02 \%$ pre term and $98 \%$ term baby. In hypertensive mothers $90 \%$ live birth and $10 \%$ intra uterine death and in non-hypertensive mothers $100 \%$ live birth.

The above table suggest that placenta of hypertensive mother were $58 \%$ discoid in shape and non-hypertensive were $98 \%$ discoid in shape. In hypertensive mother hematoma present in $16 \%$ and in non-hypertensive hematoma were absent. In hypertensive mother infarction were present in $80 \%$ cases and in non-hypertensive present in $2 \%$ cases. In hypertensive mother calcification present in $46 \%$ and in non-hypertensive present in $16 \%$ cases.

\section{Table 6: Other placental finding}

Table 6: Other placental finding
\begin{tabular}{|l|l|l|l|l|}
\hline \multirow{2}{*}{$\begin{array}{l}\text { Variable placental } \\
\text { feature }\end{array}$} & \multicolumn{2}{|l|}{$\begin{array}{l}\text { Hypertensive } \\
\text { (No.50 Cases) }\end{array}$} & \multicolumn{2}{l|}{$\begin{array}{l}\text { Non hypertensive } \\
\text { (No.50 Cases) }\end{array}$} \\
\cline { 2 - 5 } & Mean & SD & Mean & SD \\
\hline Placenta weight & 470.38 & \pm 60.21 & 506 & \pm 24.32 \\
\hline Placenta diameter & 18.20 & \pm 0.82 & 19.6 & \pm 0.78 \\
\hline Placenta thickness & 2.04 & \pm 0.61 & 2.38 & \pm 0.21 \\
\hline Cotyledon & 16.82 & \pm 3.04 & 18.5 & \pm 2.15 \\
\hline Foeto placental ratio & 5.81 & \pm 0.2 & 5.7 & \pm 0.61 \\
\hline Placental Area & 208.6 & \pm 10.54 & 216.9 & \pm 0.40 \\
\hline
\end{tabular}

\section{Discussion \& Conclusion}

The present study was conducted in the department of Anatomy, Shree B.K. Shah Medical institute \& Research Centre, in collaboration with the Department of Obstetrics and Gynecology of Dhiraj hospital, Piparia, Vadodara. A total number of 100 placenta(Fifty hypertensive mother + fifty normal mother) with $5 \mathrm{cms}$ length of umbilical cord were collected from the Obstetrics department and relevant medical history of the mother were noted from the data available in the Hospital records.

Pregnancy induced hypertension adversely affects the morphology of placenta. Placenta brings the mother and fetus, the two important ends of reproduction in contact with each other. Therefore the placenta which is usually considered as records of infant's prenatal experience provides crucial information about the deleterious effects of pregnancy induced hypertension on fetal outcome.

Teenage pregnancy and primi gravida were risk factors for preeclampsia and eclampsia the prevalence of pre-eclampsia $(50 \%)$ and eclampsia (24\%) in this study [Table 1] Shiva shree ranga et al found similar finding of hypertensive pregnancies.

The prevalence of infarction of placenta of hypertensive mother were $20 \%$ and in non-hypertensive mother were $02 \%$.

Udaina et al and Majumdar and Correa et al found similar finding in their studies.

\section{References}

1. Wang, W. S., Liu, C., Li, W. J., Zhu, P., Li, J. N. and Sun, K. (2014). Involvement of CRH and HCG in the induction of aromatase by cortisol in human placental syncytiotrophoblasts. Placenta, 35(1): 30-36.

2. Sørensen, A., Peters, D., Fründ, E., Lingman, G., Christiansen, O. and Uldbjerg, N. (2013). Changes in human placental oxygenation during maternal hyperoxia estimated by blood oxygen leveldependent magnetic resonance imaging (BOLD MRI). Ultrasound in Obstetrics and Gynaecology, 42(3): 310-314.

3. Raghunath, G. and Vijayalakshmi, V. S. (2011). A study on the Morphology and the Morphometry of the Human Placenta and its Clinical Relevance in a population in Tamilnadu. Journal of clinical and diagnostic research, 5(2): 282-286.

4. Singal, D. R., Sarvaiya, D. J. and Patel, S. V. (2013) Placental Morphometry in Relation to Birth Weight of Full Term Newborn. Southeast Asian Journal of Case Report and Review, 2(5): 334-342.

5. Tissot van Patot, M. C., Valdez M., Becky V., Cindrova-Davies T., Johns J., Zwerdling L., Jauniaux E. and Burton G. J. (2009). Impact of Pregnancy at High Altitude on Placental Morphology in Nonnative Women with and Without Preeclampsia. Placenta, 30(6): 523-528.

6. Heazell, A., Cotter, S., Gallimore, L., Greenhalgh, D., Kennedy, S., Klika, V., Kritz, M., Nielsen, P., Preedy, K., Pu, I., Setchi, A., Siggers, J. and Whittaker, R. (2010). Comparing placentas from normal and abnormal pregnancies.

7. Janthanaphan, M., Kor-Anantkul, O. and Geater, A. (2006). Placental weight and its ratio to birth weight in normal pregnancy at Songkhlanagarind Hospital. Journal of Medical Association Thailand, 89(2):130-137.

8. Kaplan, C. G. (2008). Gross Pathology of the Placental Weight, Shape, Size, Colour. Journal of Clinical Pathology, 61(12): 12851295.

9. Panti, A. A., Ekele, B. A., Nwobodo, E. I. and Yakubu Ahmed (2012). The relationship between the weight of the placenta and birth weight of the neonate in a Nigerian Hospital. Nigeria Medical Journal 2012 April-June, 53(2): 80-84.

10. Lakshmi, D. C. K., Shashank, N. and Raghupathy, N. S. (2013). Morphological Studies of Normal Human Placenta at Different Gestational Periods. Journal of Dental and Medical Sciences, 6(3): 2279-0861.

11. Lo, Y. F., Jeng, M. J., Lee, Y. S., Soong, W. J. and Hwang, B (2002). Placental weight and birth characteristics of healthy singleton newborns. Acta Paediatr Taiwan, 43(1): 21-25.

12. Little, R. E., Zadorozhnaja, T. D., Hulchiy, O. P., Mendel, N. A., Shkyryak-Nyzhnyk, Z. A., Chyslovska, N. and Gladen, B. C. (2003). Placental weight and its ratio to birthweight in a Ukrainian city. Early Human Development Journal, 71(2): 117-127.

13. Tangirala S, kumari D. Placental morphology in hypertensivedisorders and its correlation to neonatal outcome. IAIM, 2015;2(11):35-38.

14. EskildA,Vatten LJ. Do pregnancies with PE havesmallplacentas? A 


\section{Parmar et al; HHuman Placenta in Narmal and Htypertensive Pregnancy}

population study of 317688pregnancieswith \& without growth restriction in theoffspring.BJOG. 2010; 117:1521-1526.

15. Udaina.A, Bhagwat SS, Mehta CD, Relation between placental surface area, infarction and foetal distress in pregnancy induced hypertension with its clinical relevance. J AnatSocInd 2004;53;1:2730 .

16. MajumdarS,Dasgupta H. A Study of Placenta In Normal And Hypertensive Pregnancies. . J AnatSocInd 2005;54:1-9.

17. Cavellani, Marina C. Paschoini, Flávia A. Oliveira,Luís C. Peres, Marlene A. Reis, Vicente P. A. Teixeiraand Eumenia C. C. Castro Placental morphometrical and histopathology changes in the different clinicalpresentations of Hypertensive Syndromes inPregnancy. Arch Gynecolobstr 2008;277(1):201-206.

18. Kurdukar MD, Deshpande NM. Placenta in Pregnancyinduced Hypertension. Indian J PatholMycrobiol 2007;50:493-497.

19. Manik Sirpurkar, Vaibhav Prakash Anjankar. Studyof correlation between placental morphology and adverse perinatal outcome in different conditionsaffecting pregnancy. Int J Reprod Contracept ObstetGynecol. 2015;4(4):1165-1168.

20. Benirschke.K, Kaufmann.P, Baergen R. Pathology ofthe Human Placenta. 5th edition, Vol.Chapter.7 Architecture of normal villous trees, New York. Springer Verlag.2006:121-159.

21. Carolyn M. Salafia, Michael Yampolsky, Dawn PMisra, Oleksander Shlakhter, Danielle Haas, Barbara Eucker, and John Thorp. Placental surfaceshape, function, and effects of maternal and fetal vascular pathology. Placenta. 2010;31(11): 958-962.

22. Choe Jing Jye.Challenges of obstetricians in themanagement of severe preeclampsia.Obs andGynaec today. 2009; 16(8): 348-51.
23. Emery SP. Hypertensive disorders of pregnancy:Overdiagnosis is appropriate: Cleveland Clin J Med. 2005; 72(4): 21-28

24. Bewly S, Coper D, Campbell S. Doppler investigationof uteroplacental blood flow resistance in thesecond trimester. A screening study forpreeclampsia and intrauterine growthretardation.B J Obst and Gynecol. 1991; 98: 871-79

25. Alvarez H, Medrano CV, Sala MA, BenedettiWL.Trophoblast development gradient and its relationship to placental hemodynamics II.Study offetal cotyledons from the toxemic Placenta.Am JObstet Gynecol. 1972; 114: 873-78

26. Segupta Kishwara, ShamimAra, Khandaker AbuRayhan ,Mahamuda Begum. Morphological Changes of Placenta in Preeclampsia.BangladeshJournal of Anatomy January 2009; 7(1): 49-54.

27. Zhou Y, Danisky C.H, Fisher S.J. Preeclampsia isassociated with failure of human cytotrophoblast to mimic a Vascular Adhesion Phenotype J. Clin. Investigation. 1997; 99 (9): 2152-2164.

28. Udaina A, Bhagwat SS, Mehta CD. Relation between placental surface area, infarction and foetal distress in pregnancy induced hypertension with its clinical relevance. JAnat Soc India 2004;53:2730.

29. Majumdar S, Dasgupta H. Astudy of placenta in normal and hypertensive pregnancies. JAnat Soc India 2005;54:1-9.

30. Corrêa RR, Gilio DB, Cavellani CL, Paschoini MC, Oliveira FA, Peres LC, et al. Placental morphometrical and histopathology changes in the different clinical presentations of hypertensive syndromes in pregnancy. Arch Gynecol Obstet 2008;277:201-6

Copyright: (C) the author(s), publisher. Academia Anatomica International is an Official Publication of "Society for Health Care \& Research Development". It is an open-access article distributed under the terms of the Creative Commons Attribution Non-Commercial License, which permits unrestricted non-commercial use, distribution, and reproduction in any medium, provided the original work is properly cited.

How to cite this article: Parmar KM, Vaishnani H, Shah GV. Morphological Study of Human Placenta in Normal and Hypertensive Pregnancy. Acad. Anat. Int. 2019;5(2):1-4.

DOI: dx.doi.org/10.21276/aanat.2019.5.2.1

Source of Support: Nil, Conflict of Interest: None declared. 